\title{
Nurse Leaders as Stewards: The Beginning of Change
}

\author{
Norma Sinnott Murphy*
}

\author{
School of Nursing, Dalhousie University, Halifax, Nova Scotia B3H 4P5, Canada
}

\begin{abstract}
In understanding fully persons' moral predicaments, a core component of forming perceptual judgments, nurses may need to shift the epistemology of their practice from instrumental reasoning, or means-ends thinking, integrating a virtue-based practical reasoning. A bearing witness that achieves understanding of clients' moral qualities is attained through the articulation of nurses' self-identities within matrices, such as MacIntyre's theory of virtue ethics and standards and codes of ethics. Moreover, nurse leaders who exercise stewardship could apply the concept of communities of inquiry to structure learning conditions by which nurses may engage in experiential learning. This leadership enhanced by the nurse steward's phronetic knowledge, or practical wisdom, which guides understanding of how the clockwork of practical reasoning may evolve within such communities, is critical to nurses' shift in reasoning. Nonetheless, nurse leaders need empirical evidence to comprehend how stewards' accumulated moral insights may shape their character qualities, hence selection of values upon which to act in facilitating nurses' self-expression.
\end{abstract}

Keywords: Bearing witness, moral agents, nurse stewards, practical reasoning, virtue-ethics.

\section{INTRODUCTION}

Nurse stewards hold the potential to inform meaningful change in nursing practice, owing to their capacity to act upon their character qualities, including self-discipline and courage [1], as well as engage in practical reasoning, by which the intrinsic value or good of a situation is preserved and promoted [2,3]. Magill and Prybil [4] stressed that who we are - our ethical principles - and how we make decisions how we function - informs what we do, and further, that through the exercise of stewardship, quality health-care environments that embody high standards of care evolve. Nurse leaders who exercise stewardship at points of service could assist nurses to advance their practice of bearing witness or being present to clients [5] as they seek to transcend experiences of disease, illness and suffering [6]. Nurses, however, are accustomed to engaging in instrumental reasoning, or applying general principles [7] to guide their responses to clients' medical conditions. In bearing witness, nurses must act upon their moral agency in relating sensitively to the particularities of persons' lived experiences. To practice bearing witness, some nurses may need to shift the epistemology of their practice from instrumental reasoning, or applying of general principles [7], integrating a virtue-based practical reasoning. In preserving and promoting nurses' capacity to respond to clients with sensitivity, both nurse stewards and practicing nurses may contribute to the evolution of quality health-care environments.

In being present to clients, nurses must "understand fully or appropriately" [8] the moral features of the other's lived experience, or interpret the nature of the person's situation, in order to select values and principles to act upon, and thus

\footnotetext{
*Address correspondence to this author at the School of Nursing, Dalhousie University, Halifax, Nova Scotia B3H 4P5, Canada; Tel: 902-494-2223; Fax: 902-494-3487; E-mail: Norma.Murphy@dal.ca
}

yield opportunities for persons to bring narrative unity to their lives. MacIntyre $[9,10]$ reinforced this notion when he advised that, in bringing about coherence in our lives, we must learn to perceive the nature of the situations in which we find ourselves, their intrinsic goods and potential harms and temptations, and what virtues or character qualities are necessary in reasoning and forming practical judgments about what is the best for the self and others. Thus, the practice of bearing witness begins with the process of bringing historical, particular elements of the background context to the foreground by interpreting the nature of the background, specifically, its moral elements, as perceptual awareness is refined. Nurses may further refine this awareness as they gain insight into their emotions associated with persons' lived experiences and cognitively appraise the meaning of those experiences [8]. In this learning process, nurses can articulate their understanding of what they are taking-in or what is registering about a situation - their perceptional awareness - by identifying the focus of the object of their emotions, and how the focus and their understanding of it has come to be understood as significant [8]. In spite of multiple interpretations, the interpretation that generates the greatest force is taken as mattering; and hence, moral elements of the background may be fully understood or discerned and brought to the foreground.

Nurse stewards may facilitate nurses' shift in their epistemology of practice by applying the concept of communities of inquiry $[11,12]$ at points of service, such as hospital nursing units, whereby nurses may appraise, emotionally and cognitively, their nursing experiences in conversation with one another. This forum provides opportunities for gaining insight into the applicability of nurses' professional standards and code of ethics, and thus nurses may inform their professional self-identities as fundamental to their practical reasoning. Empirical evidence indicated that many nurses experience anguish in reflecting on how to act morally amidst conflict and ambiguity in their 
practice settings [13]. The concepts of stewardship and communities of inquiry as a pedagogy of education for nurses' professional self-development may be pertinent to nurses' evolving practice of bearing witness.

\section{PAPER OBJECTIVES}

In this paper, the writer will: a) discuss the importance of the metaphor, "the steward," as a leader who has the potential to inform meaningful change - through phonetic knowing $[7,14]$ - and thus preserve and promote what is good $[2,3]$ in a nursing environment, specifically the practice of bearing witness; b) offer MacIntyre's [9] theory of virtue ethics as a frame of reference to conceptualize how nurses may enact their moral agency, thus shifting their epistemology of practice from predominately instrumental reasoning, integrating virtue-based practical reasoning; c) explore how emotional attunement [8] toward a situation catalyzes experiential learning by which perceptual awareness is refined and full understanding is attained; d) examine Doane's [13] findings that suggested nurses' need for a pedagogy of education that supports the formation of their professional identity as moral agents; e) supply the concept of communities of inquiry $[11,12]$ as a pedagogy of education for nurse stewards who desire to encourage nurses to shift the epistemology of their practice, integrating virtuebased practical reasoning; and, f) suggest implications for nursing research, including how the nurse steward's character-identity shapes his or her practical judgments.

\section{STEWARDSHIP AS A CONCEPTUAL FOUNDATION FOR NURSING LEADERSHIP}

Stewardship is a concept that offers nurse leaders critical insight into how they can assist nurses to shift their epistemology of practice, integrating a form of practical reasoning that is virtue-based, and hence extend their practice of bearing witness. From its early biblical beginnings, the word "steward" has been developed from the term stigwaerd, meaning the warden of the house [3] and has more recently developed as an environmental or ecological term. More specifically, the forward-thinking theorist Paterson suggested that stewardship may be thought of as the exercise of tilling the environment through which the "intrinsic value" is preserved and protected. He extended his perspective by indicating the responsibility for the wellbeing of the environment as a whole is shared by all persons. In supplying her own addition to this ecological standpoint, Welchman [1] asserted that stewards devote their time and thoughts in an effort to sustain and improve "the conditions of some things(s) and person(s), and not primarily for one's own sake", a devotion grounded in "human-centered virtues of character", including self-discipline and courage. A steward has thus been described as "a person who preserves and promotes" [2] "the intrinsic value" [3] of situations through "wise management" [3], or practical reasoning, respecting the capacity of all to contribute to that good.

Wunderlich [15] posed a question that is relevant to nursing stewardship that aims to encourage nurses to act on their moral agency in such experiences: how is stewardship exercised? This question may be extended to inquire, what does it mean for the steward to till the environment, or, according to Wunderlich, to perceive the whole and yet select one course of action to preserve and promote the intrinsic good of a situation? In other words, how is the environment managed with wisdom, as suggested by Paterson? [3] In answering these questions, a nurse steward may comprehend with some assurance how he or she may encourage nurses to act on their moral agency as they seek to understand fully the nature of persons' lived experiences.

Although authors argued that stewards preserve and promote what is intrinsically valuable within their environments, a theoretical context is needed to understand how they gain a discerning insight into the moral features of their environment, more precisely, how stewards may understand the wholeness and particularity of situations and respond in a disciplined manner. Aristotle's concept of phronesis, a practical wisdom that supplies a person with insight into how an entity comes to perform its function well [16], was employed by Cook and Leathard [14] to premise their exposition on clinical leadership, whereby they argued that phronesis ought to be the foundation of this change. This practical knowledge also lends support in articulating how a steward may till the environment, or in this case, preserve and promote what is intrinsically valuable in a nursing environment: the practice of bearing witness. In tending both the wholeness and particularity of a situation, nurse stewards may encourage nurses at the point of service to shift their epistemology of practice, and thus a brief explanation of phronesis will follow.

In their depiction of phronesis, Cook and Leathard [14] contended that praxis is "a practical form of knowledge that generates actions" through which a leader incarnates his or her beliefs. Cook and Leathard argued further that engagement in praxis results in the development of practical wisdom, or phronetic knowing, a kind of knowing that "draws on experience, understanding and internal values to inform practice", and arises through continuous dialogue between a lived experience and insight acquired from theory and action. This depiction of practical wisdom is extended by including Aristotle's distinction between phronesis and techne, where techne refers to the ability to produce or make and is expressed as a skill or technique [7]. In contrast, phronesis is involved or entwined in the operation of praxis and embodies a "judgment of wisdom," [7] where a learning process evokes a moral insight.

Stewardship may be exercised through phronetic knowing rather than techne, specifically, through dwelling with a lived experience, drawing on understanding, and gaining awareness of values embedded in the practice of stewardship as a methodology for discerning what is significant in an experience. Phronetic knowing also grounds the formation of judgment about the values and principles that ought to be acted upon to preserve and promote what is intrinsically good in such an experience. This knowledge is informed by dialogue between the lived experiences, theory and practice. The moral insights evoked through this selfinterpretation accumulate, thus rendering the steward competent in appraising a situation in its entirety, and in doing so, learning how to judge how to act, thus incarnating his or her beliefs. Magill and Prybil [4] asserted that this act of critical, experiential learning - pivotal to stewardship ought to be the foundation of health-care organizational ethics, due to the steward living out his or her values in daily practices. They premised this argument on the notion that, in 
order to function effectively, or make appropriate decisions, leaders must be mindful of their self-identity, a tool for practical guidance in perceiving tensions in the economic, social and political environments of health-care delivery. By dwelling in the tensions and uncertainty, a dialogue between those tensions, theory and the practice of stewardship, a nurse leader may develop phronetic knowing by which he or she understands a situation in both its entirety and particularity, and thus Aristotle's concept of phronesis assists nurses to shift their epistemology of practice, integrating a form of virtue-based practical reasoning.

In practice settings, this phronesis-lead shift can be recognized in nurses' openness to clients' by respecting their capacity to be authentic, in the way nurses assist clients to express their feelings, and in how they encourage clients to gain insight into their needs and their potential satisfaction. In this nurse-person encounter, both nurse and client bend and respond so that new understandings can emerge as a context for the client's self-development [17].

Leadership has been characterized as transformative, whereby nurses are inspired to participate in setting visions for health-care organizations that promote the greater good [18], an inspiration often merely realized by the leader's charisma. Nurses, however, need to act on their moral agency to perceive and understand the moral features of persons' experiences, such as suffering, and bring them under one description [9]. Practitioners are accustomed to using predominately instrumental reasoning: a shift in epistemology would require nurse leaders to encourage practitioners to "change their ways of thinking" [14]. integrating a form of virtue-based practical reasoning. Nurse stewards may foster this shift by providing nurses with opportunities for the enhancement of their phronetic learning that draws on experience, understanding and values embedded in their professional practices. Similar to the selfcritique by the steward, nurses' evaluative processes would also entail a constant dialogue between the lived experience and insight acquired from theory and practice.

\section{VIRTUE ETHICS: A STEWARDSHIP CONTEXT THAT FACILITATES NURSES' SHIFT IN EPISTEMOLOGY}

Although the nurse steward ought to structure educational opportunities that encourage nurses to shift their epistemology of practice, integrating a virtue-based practical reasoning, a gap remains to be filled by the steward's theoretical lens. MacIntyre's [9] theory of virtue ethics, which is founded in Aristotle's concept of phronesis, provides such a lens. This theory extends understanding of virtue-based practical reasoning, due to its explanation of how character qualities - or self-identity - influence practical reasoning, specifically how a moral insight may be evoked through a critical appraisal of situations generating conflict and ambiguity. The nature of lived experiences may be appraised through drawing on experience, understanding and values, as well as a continuous dialogue between the experience and theory and practice. This theory finds itself dual premised: it embraces a form of realism, specifically, that human experience and sensitivity can yield a knowledge of moral reality whose properties exist outside subjective awareness [19]; and secondly, it is grounded in a teleological form of understanding that accepts the end's or goal's primacy $[7,9]$.

Recall that the nursing practice of bearing witness or being present to others' self-expression entails a capacity to understand fully or appropriately the historical, particular features of persons' experiences - an essential component in the epistemology of nursing. By engaging in virtue-based practical reasoning, nurses can expand their consciousness of the values and principles upon which to act, and, in this selfarticulation, may not only perceive the meaning of persons' lived experiences fully - through an emotional and cognitive appraisal of experiences - but also select pertinent courses of action that assist persons in bringing narrative unity to their lives. MacIntyre $[9,10]$ advised that we must learn to perceive the kind of situations we find ourselves in, their intrinsic goods and potential harms and temptations, and what virtues are necessary in reasoning and forming practical judgments. With this argument, he reinforced the assertion that, in bearing witness to persons' lived experiences, nurses must understand fully the moral features of the other's lived experience, or interpret the kind of situation the person is experiencing and select a value or principle to act upon. At the inception of this practice is the endeavor of bringing historical, particular elements of the background to the foreground by understanding the background's moral elements as perceptual judgments are refined. What enhances this change is the ability to remove the historical, particular elements from a series of interpretations and narrow them under one such description, resulting in the "degree and kind of coherence (in the experience to be brought out)" [9]. Whether and how the moral elements are perceived is contingent on the self-identity of the person approaching the situation.

With its account of how persons become their authentic selves, MacIntyre's [9] theory of virtue ethics supplies nurse stewards with a context for assisting nurses to enact their moral agency, thus understand fully clients' moral realities. In accordance with this theory, a person understands fully his or her lived experiences as a life-long narrative quest that is influenced by social settings or institutions, as well as by practical reasoning. More specifically, MacIntyre asserted that a person is a narrative self who seeks the good, "telos", as he or she gains insight into the meaning of everyday experiences, a self-critique realized under the auspice of a social setting, and by which a virtuous self-identity is formed. A social setting, according to MacIntyre, embodies goals, values or virtues - character qualities - which are essential for the realization of the goals, and a judgmental continuity that is based in a unified set of beliefs. Moreover, the theorist contended that self-identity, informed through the cultivation of character qualities, is essential to bringing about coherence, due to the influence of identity in shaping perceptual judgments about what is morally relevant in a situation. This is to say, a moral disposition or personal comportment informs what one perceives in an experience, as well as how those features are interpreted - or brought to the foreground - and acted upon. MacIntyre also argued that the exercise of character is requisite to the engagement in practical reasoning that he defined as the capacity to apply general principles in particular cases, based on four elements, the first of which is the person's goals. The second is the major premise that doing, having or seeking a specific 
goal is what is good for or needed by the person, and the third element is the minor premise wherein the person, relying on perceptual judgment, asserts that this a requisite instance. The final element in the practical reasoning is that of the action. In understanding fully the moral elements of an experience, a person can identify who one wants to become in relation to that good, thus choosing the right action by which to preserve and promote the good for the self [2].

To engage in the practice of bearing witness, nurses must, in accordance with MacIntyre's [9, 10] perspective, perceive what lies at the heart of a situation, its intrinsic good and potential harms and temptations, and what virtues are necessary in reasoning and forming practical judgments. In engaging in an emotional and cognitive appraisal, nurses may be guided by professional settings that embrace standards and codes of ethics. The settings are contexts for discerning values and principles upon which to act in nurses' everyday practice. The question remains nonetheless, how might a nurse refine his or her perceptual awareness of what lies at the heart of another's experience, more precisely, how is a background context, such as a perception of an event, moved to the forefront of one's awareness? This point of inquiry must be understood by nurse leaders who exercise stewardship with the intent of encouraging nurses to engage in virtue-based practical reasoning, specifically as they gain awareness of the meaning of their everyday nursing experiences.

\section{EMOTIONAL ATTUNEMENT AND THE REFINEMENT OF PERCEPTUAL AWARENESS}

Out of a predominately cognitive-focused understanding of reasoning, nurses can shift their epistemology of practice, integrating virtue-based practical reasoning [9] as they refine their perceptual awareness of the moral features of an experience, and thus select values and principles to act upon. The point of access to refinement of perceptual awareness is emotions generated by experiences. The belief that emotions are essential in understanding moral realities premises virtuebased practical reasoning, an idea expressed by Starkey [8], who asserted that emotions are vital to moral understanding. Emotions affect the perception and understanding of an experience, as Starkey explained, "the right emotions" must be present in order to fully or appropriately understand the meaning of an object. By appraising the emotions, we can uncover what MacIntyre $[9,10]$ deemed as necessary to a situation's accurate interpretations: the learning to perceive what lies at its foundation, its intrinsic values and potential limitations, and what virtues are necessary to guide a response. This bringing forth of the elements requires an awareness and evaluation of the "peculiarities and nuances" [8] of an experience and knowing what is applicable. To reduce a misunderstanding generated by inaccurate emotions, a person may need to alter these emotions, thus fully interpret the situation. An emotional attunement to what is unique about a situation is the beginning point of a learning process by which perceptual awareness may be refined, and values and principles may be selected and acted upon.

The claim that emotions affect awareness of an object and a full understanding of the peculiarities and nuances of an experience is premised on two assertions about the nature of emotions. As persons live in their worlds, they apprehend people, events and situations [8]. This apprehension is a cognitive state distinct from an explicit belief about an object, and is a registering of change or a perception of an object, understood as a "seeing as". The person gains "awareness of the object of [his or her] emotion" as he or she receives information "provided by the activation of background beliefs and association, as well as percept[ions]". First, emotions entail a cognitive "apprehension" or perception of the emotion's object, and secondly, a state of affective arousal, visceral tension, or a "psychic feeling". In an emotional situation, a person is aware of the cognitive element in terms of the affective element, and the affective element in terms of the cognitive. For example, in the case of anger related to an insult by another, Starkey [8] argued, the visceral tension and heart rate is interpreted in terms of the insult. An experiential association joins affective and cognitive elements, meaning, information about affective changes enters into the representation of the object of the emotions, and the registering of the changes becomes part of the emotion's content.

This experiential association focuses attention on what is significant about the object of the emotion [8]. Emotions play a role in focusing attention on a narrow range of objects. The ability of a stimulus, such as voice tone, to trigger an emotional response increases the perceptibility of the stimulus. The perceptual awareness enables the gathering of more information about the object, including associated ideas and memories. Feelings and thoughts are registering; a change is initiated. Moreover, the force of the experiential association that joins the cognitive and affective elements of an emotion gives this discernment process its depth. Some objects have more import, or significance owing to their force: "We feel that the object of the emotion has acted upon us" [8]. The importance attached to the object reflects our values, interests and goals, thus part of the import is determined by the force of the emotional representation that provides a sense of the object's significance.

From the values found in their professional setting, nurse stewards may not only assist nurses to focus on the experiential association between cognitive and affective elements of the object of emotion, but also to bring to the foreground the moral elements of both client experiences, and those of the nurse, as they seek to comprehend fully the situation. More precisely, in acting upon values and principles, found in their professional setting, nurses can engage in practical reasoning that embodies a refined perceptual awareness of a situation's salient features, identification of the relevant goods and harms, and the virtues that are needed to guide a response $[9,10]$. Once nurses have determined what is registering in a situation, they become open to the possibility of shifting their epistemology of practice to a virtue-based form of practical reasoning, particularly if nurses are influenced by their standards and codes of ethics. Yet, empirical evidence suggested that, although nurses do reflect upon their moral identity, some nurses may need educational conditions by which they feel encouraged to articulate their professional characteristics, and extend their capacity to respond sensitively to the particularities of persons' lives. 


\section{NURSES REFLECT ON THEIR MORAL IDENTITY}

In a qualitative inquiry into nurses' reflections on their moral identity, a prominent Canadian nurse researcher concerned with nursing ethics, Gweneth A. Hartrick Doane [13], uncovered that nurses described themselves as moral agents whose identity had narrative, dialogical and relational contexts. Doane's findings, however, did not reveal how nurses' identities were explicitly informed; rather, she reported nurses use of contemporary language of consensus building and negotiation [20] in their ethical decisionmaking, terms which typically signify power politics of policy-making, not the selection of principles and values to incarnate in nursing practice. More specifically, in shaping their moral identities, the nurse participants reported telling stories of situations in which they perceived themselves as acting or failing to act ethically. In interpreting the data, Doane suggested that by constructing these narratives, nurses offered "reason[s] and justification for actions", thereby attempting "to create a 'fittingness' between their identity and action", more-so than a discernment of rightness. The investigator also emphasized that the data demonstrated that nurse participants conducted an "inner dialogue" in relation to ethical nursing experiences, listening to "different voices in them... in reaching a consensus within themselves". In addition to this inner dialogue, the nurses' moral identities emerged through "layers of negotiation with the self, with others, and within the social organization", and their identity as an '"ethical nurse' was a reality constructed in the relational moment". Doane's research also revealed the power of the collective influence; this entity's value, which is tacitly deemed right or wrong, informed participants' identity and self-perception. Beyond bringing forth a description of nurses' moral identities as narrative, dialogic and relational, the researcher did not fully elaborate how nurses discerned or acted upon their ethical knowledge, even posing the question that if "nurses' moral identities are narrative, relational and contextual, how can nurses' exercise their moral agency" within institutions that harbor tension and ambiguity toward nurses' ethical commitments.

Nonetheless, Doane's [13] empirical evidence showed that nurses believed they are answerable or have an ethical responsibility to the persons whom they serve. To preserve and promote their moral answerability - hence advance their practice of relating sensitively to the particularities of persons' experiences - at least some nurses may need a conceptual matrix, and, MacIntyre's [9] theory of virtue ethics supplies such a framework, both theoretically and practically. More precisely, the theory, with its emphasis on settings, such as standards and codes of ethics, extends understanding of how nurses may act upon their perceptual judgments about the moral features of their practices as they develop their professional identity, or character. In engaging in virtue-based practical reasoning, nurses are no longer using the language of consensus-building among the different voices within the self or negotiating with the self or others in reflecting upon nursing practices, but are instead articulating consciously and explicitly values and principles to inform their professional identity. And thus, within the context of MacIntyre's virtue ethics, nurses may feel confident in their capacity to understand what is registering in their practice and how to respond to its moral features as they engage in self-interpretation.

A new face of leadership is needed to facilitate nurses' preservation and promotion of their practice of bearing witness, moreover, their capacity to articulate their professional self-identity. Typically, leaders have conceptualized leadership as inspiring practicing nurses to adopt the leaders' perspectives on health-care reform [18]. In reality, visions worthy of actualization exist in the minds of both the leader and the practicing nurses - with nurses acting in respect for the dignity of all persons - and so leadership requires an ability to bring to fruition the goals of both parties. This leadership can invoke moral insights that nurses need to justify a shift in their epistemology of practice, integrating a virtue-based practical reasoning. With this new face, we have moved beyond an emphasis on leaders' charisma as the driving force in change, and, instead, refocused leaders as stewards who apply practical wisdom or judgment in achieving a vision, as well as encourage all nurses to participate in such a change process. Educational conditions at the point of service, set up by stewards, can encourage nurses in their self-expression and hence, moral responses to the feelings and needs of the persons whom they serve.

\section{COMMUNITIES OF INQUIRY: A PEDAGOGY OF EDUCATION FOR NURSES' PROFESSIONAL SELF- DEVELOPMENT}

The development of nurses' professional self-identity cannot be elusive; moreover, some nurses may appreciate educational conditions that support their self-expression, as empirical evidence suggested. Communities of inquiry or discursive communities $[11,12]$ are viewed as a medium for the evolution of narrative and dialogical self-identities [21]; meaning, the articulation of who nurses desire to become, individually and collectively, within the context of relatedness to self, others, and professional settings. Thus, the concept communities of inquiry may be a pedagogy of education by which nurse stewards can encourage nurses at the point of service to appraise - together - the moral features of their everyday nursing practices. Within these discursive communities, nurses could apply MacIntyre's [9] theory of virtue ethics to shift their epistemology of practice from instrumental reasoning, integrating a virtue-based practical reasoning. To illuminate, nurses could interpret their experiences in relation to their professional setting, including standards and codes of ethics, and thus develop their professional self-identities as they refine their perceptional awareness of their experiences. More specifically, within communities of inquiry, nurse stewards may encourage nurses to engage in a continuous dialogue between their experiences and insights acquired through theory and practice. In fully understanding the kind of situations they are experiencing, nurses can select values and principles upon which to act.

\section{IMPLICATIONS FOR NURSING RESEARCH}

By lingering on the thinking that charisma can inspire practicing nurses to adopt leaders' vision for health-care reform, we do not encourage nurses to articulate and enact their own moral agency, a fault that hinders the development of nursing practice that responds sensitively to the moral 
features of persons' experiences, and hence transcendence of suffering. A moving beyond into the exercise of stewardship, whereby the steward preserves and promotes what is intrinsically good in nursing practice, specifically the bearing of witness, is requisite to nurses' contribution to the evolution of quality health-care environment. As a steward, the nurse leader identifies the nurses' practice of bearing witness to the moral features of persons' experiences as critical, develops his or her practical judgment that includes a perspective both entire and particular of the practice environment, and includes all nurses in the discourse of selfinterpretation. Recall, in the formation of his or her practical judgment, the steward draws on experience, understanding and internal values, which, when incarnated, form the steward's character that yields his or her practical judgments about what features to bring to the foreground and act upon in encouraging nurses to act on their moral agency. The nursing profession needs nurse leaders who as stewards can identify the salient features among the whole that must be activated in order to bring about change. Nevertheless, explicit theoretical insight is needed into examples of nurse stewards who perceived the whole and elected one course of action that supported nurses in the enactment of their moral agency. Of particular interest is how nurse stewards' moral insights, accumulated through experiential learning, shaped their character identities, thus grounding their discernment and selection processes.

\section{REFERENCES}

[1] Welchman J. The virtues of stewardship. Environ Ethics 1999; 21: 411-23.

[2] Murphy N, Roberts D. Nurse leaders as stewards at the point of service. Nurs Ethics 2008; 15 (2): 243-53.

[3] Paterson J. Conceptualizing stewardship in agriculture within the Christian tradition. Environ Ethics 2003; 25: 43-58.

[4] Magill G, Prybil L. Stewardship and integrity in health care: a role for organizational ethics. J Bus Ethics 2004; 50: 225-38.
[5] Cody W. The ethics of bearing witness in healthcare: a beginning exploration. Nurs Sci Q 2004; 14: 288- 96.

[6] Murphy N, Aquino-Russell C. Nurse's practice beyond simple advocacy to engage in relational narratives: expanding opportunities for persons to influence the public space. Open Nurs J 2008; 2: 40-7.

[7] Carr D. Character in teaching. Br J Educ Stud 2007; 55: 369-89.

[8] Starkey C. Emotion and full understanding. Ethic theory moral practice. 2008 [Online]. Available from: http://www.springer link.com $/$ content $/ 102880 /$ ?Content + Status $=$ Accepted\&sort $=$ p_Onli neDate \&sortorder $=\operatorname{desc} \& v=$ condensed $\& p=5 \mathrm{e} 7 \mathrm{ad} 60795 \mathrm{c} 4473 \mathrm{da} 7 \mathrm{~d}$ 7679 fab 6 fe 4 ee $\&$ o $=10$

[9] MacIntyre A. After virtue: a study in moral virtue. Notre Dame, Indiana: University of Notre Dame Press 1984.

[10] MacIntyre, A. Dependent rational animals why human beings need the virtues. Chicago: Open Court Publishing 1999.

[11] Lipman M. Thinking in education. $2^{\text {nd }}$ ed. New York: Cambridge University Press 2003

[12] Splitter LJ. Do the groups to which I belong make me? Reflections on community and identity. Theory Res Educ 2007; 5(3):261-80.

[13] Doane GA. Am I still ethical? The socially-mediated process of nurses' moral identity. Nurs Ethics 2002; 9 (6): 623-35.

[14] Cook M, Leathard H. Learning for clinical leadership. J Nurs Manag 2004; 12: 436-44.

[15] Wunderlich G. Evolution of the stewardship idea in American country life. J Agric Environ Ethics 2004; 17(1): 77-93.

[16] Brinkmann S. The topography of moral ecology. Theory Psychol 2004; 14: 57-80.

[17] Benner P. The roles of embodiment, emotion and life world for rationality and agency in nursing practice. Nurs Philos 2000; 1 : 5-19.

[18] McCallin A. Interdisciplinary team leadership: a revisionist approach for an old problem? J Nurs Manag 2003; 11: 364-70.

[19] Nortvedt $\mathrm{P}$, Nordaug $\mathrm{M}$. The principle and problem of proximity in ethics. J Med Ethics 2008; 34: 156-61.

[20] Van Kleef GA, De Dreu CKW, Pietroni D, Manstead ASR. Power and emotion in negotiation: power moderates the interpersonal effects of anger and happiness on concession making. Eur J Soc Psychol 2006; 36(4): 557-81.

[21] Taylor C. The dialogical self. In: Hiley DR, Bohman JF, Shusterman R, Eds. The Interpretive Turn: Philosophy, Science, Culture. Ithica NY: Cornell University Press 1992; pp. 304-15.

(C) Norma Sinnott Murphy; Licensee Bentham Open.

This is an open access article licensed under the terms of the Creative Commons Attribution Non-Commercial License (http: //creativecommons.org/licenses/by$\mathrm{nc} / 3.0 /$ ) which permits unrestricted, non-commercial use, distribution and reproduction in any medium, provided the work is properly cited. 